\title{
Wide Band Stop Response Using Interdigital Capacitor/CSRR DGS in Elliptical Microstrip Low-Pass Filter
}

\author{
Dristi Singhal $^{1}\left(\mathbb{D}\right.$, Shreyanshi Singh ${ }^{1}\left(\mathbb{D}\right.$, Vipul Kaushal $^{1}{ }^{\oplus}$, Amit Birwal $^{1}{ }^{1}$ \\ and Kamlesh Patel ${ }^{1 *}$ (D) \\ ${ }^{I}$ Department of Electronic Science, University of Delhi South Campus, New Delhi, India \\ dristisinghal09@gmail.com,singh06.shreyanshi@gmail.com, \\ vipul.kaushal24@gmail.com,amit.birwal@south.du.ac.in, *kpatel@south.du.ac.in
}

\begin{abstract}
In this paper, a compact elliptic-response microstrip low pass filter (LPF) is presented with a wide stop-band using stepped impedance resonators. With high attenuation in the stop-band, the overall size reduction of the proposed filter is achieved using a novel defected ground structure technique using an interdigital capacitor and complementary split ring resonator (CSRR). A 4.2 GHz LPF is designed and simulated on FR4 substrate and a stop band of $8.8 \mathrm{GHz}$ is obtained by utilizing interdigital and complementary split ring resonator. Results further show that the use of $U$-shaped high impedance line on the top layer of filter enhances the stop-band bandwidth by $2.2 \mathrm{GHz}$. In the final design, the passband insertion loss is found below $0.5 \mathrm{~dB}$, and $-10 \mathrm{~dB}$ is obtained over a band from $5.06 \mathrm{GHz}$ to $17.06 \mathrm{GHz}$ between input and output ports. The normalized circuit size of the filter is $0.417 \times 0.202$ and the figure of merit is calculated about 55 at the cut-off frequency. These proposed LPFs have promised significant advantages in the stop-band characteristics with an acceptable roll-off rate for spurious-free communications.
\end{abstract}

Index Terms - Complementary Split Ring Resonator (CSRR), Defected Ground Structure (DGS), High impedance line, Microstrip filter, Mitering, Size reduction.

\section{INTRODUCTION}

Microwave filter is designed to filter out undesired signals like outside band frequencies, harmonics, and spurious mixing products to reduce the system noise. Filters generally have frequency responses like low-pass, high-pass, band-pass and band-stop. Practically, it is difficult to obtain ideal characteristics of the filter such as zero insertion loss in the passband, infinite attenuation in stop-band with sharp transition region from passband to stop-band [1]. A stepped impedance or high-low (hi-lo) microstrip low-pass filter (LPF) is usually preferred due to properties like low insertion loss, easier design and fabrication. However, such microstrip filters have some disadvantages like gradual cut-off frequency $\left(f_{C}\right)$ response, larger size due to inductance realization, harmonics of higher order and poor stop-band characteristics [1]-[3]. To eliminate such disadvantages, many novel types of microstrip LPFs have been explored for improved stop-band performance. These LPFs involve modifications like folding the high impedance line into meandered line [4], U-shaped line [5], U-shaped resonator for gradual transition [6], spiral loaded tapered compact microstrip resonator cell [7], steppedimpedance hairpin resonator [8], novel patch resonator [9], the composition of a circular hairpin resonator and a pair of coupled parallel stepped impedance resonators (SIRs) [10], the stub-loaded coupled-line hairpin unit [11], tapered resonator [12] etc. 
Most of these designs either suffer with low attenuation $(<20 \mathrm{~dB})$ range in the stop-band or have larger size. In addition, for better roll-off rate as well as compactness, an elliptical-function response is used in many LPFs which are based on several structures, such as stepped-impedance hairpin resonator [8], tapered resonator [12], slit-loaded tapered compact microstrip resonator cell [13], symmetrically loaded radial-shape patches and meandered transmission line [14], triangular patch resonators and radial patch resonators [15], symmetrically loaded triangular and high-low impedance resonators [16], P-shaped resonators [17], novel asymmetric structures for resonator and suppressor [18], wide stop-band using tri-section stepped impedance resonator [19] etc.

Recently, a microstrip low-pass filter made using a rectangular resonator and high impedance elements is reported with a wide stop-band bandwidth of $18.7 f_{C}$ for $f_{C}=1.01 \mathrm{GHz}$ [20]. To increase the compactness of designed filter with better harmonic control, sometime a slot is made on the ground (bottom) conductor to create extra parasitic elements. Such structure is known as a defected ground structure (DGS) [21]. Various kinds of DGS designs are proposed for different filter types and explored the desired properties like compactness [2],[22], [23], sharp rejection [24], wide stop-band [25], multi-band response [26]. In some applications, sharp transition region plays a vital role for rejection of intermodulation products and so that the roll-off rate should be analyzed for these applications [27], [28]. Also, the resonant frequency of the slot can be varied by changing the number of metal fingers which are incorporated in the slot instead of changing the size of slot [29]-[32]. Also, a square-shaped complementary split ring resonator (CSRR) filtering can be used for isolation improvement [33]. Such CSRR offers high filtering (band-rejection) capability which is generally required for coupling suppression along with compact size and ease of fabrication.In this way the search for compact filter design structure with smooth curve of group delay and wide stop-band can over to use in the extensively spread microwave and millimeter-wave systems. To achieve such ideal response, approach of combining the interdigital capacitor and CSRR DGS are used.

In the presented work, the interdigital capacitor is placed as a DGS at the bottom layer to increase the stop-band region for a fifth order elliptical low-pass filter accompanied with CSRR and a wide stop band is achieved. With optimization of interdigital/CSRR DGS on the bottom layer and U-shaped high impedance line on the top layer using in CST microwave studio, we obtained the maximum stopband of about $12 \mathrm{GHz}$ (relative to $-10 \mathrm{~dB}$ ) on a physical size of only $22.22 \mathrm{~mm} \times 9.5 \mathrm{~mm}$ including $50 \Omega$ feed lines.

\section{II. $5^{\text {TH }}$ ORDER HIGH LOW ELLIPTICAL LPF (HL-ELPF)}

Design of a $5^{\text {th }}$ order HL-ELPF is accomplished using two capacitive low-impedance elements and three inductive high-impedance elements. Filter specifications are chosen as a cut-off frequency $\left(f_{C}\right)$ of $4 \mathrm{GHz}$, maximum stop-band insertion loss of $30 \mathrm{~dB}, 100 \Omega$ and $20 \Omega$ as high and low impedances, respectively and a FR4 material is taken as a substrate which has a dielectric constant $\left(\varepsilon_{\mathrm{r}}\right)$ of 4.5 and thickness of $1.5 \mathrm{~mm}$ along with copper layer thickness of $35 \mu \mathrm{m}$. 
For the $5^{\text {th }}$ order LPF design, the values of inductance $\left(L_{i}\right)$ and capacitor $\left(C_{i}\right)$ can be obtained from the immittance $\left(g_{i}\right)$ values using the following equations [2], [21].

$$
L_{i}=\frac{1}{2 \pi f_{c}} Z_{o} g_{L i}
$$

and

$$
C_{i}=\frac{1}{2 \pi f_{c}} \frac{1}{Z_{o}} g_{C i}
$$

where

$g_{L_{i}} \& g_{C_{i}}=$ normalized element values $\left(g_{i}\right)$ of the low-pass prototype filter

and, $Z_{o}=$ filter impedance $(50 \Omega)$

These lumped elements are realized by high $\left(Z_{h}\right)$ and low $\left(Z_{l}\right)$ impedance lines, whose electrical lengths can be obtained by equations (3) \& (4) [2], [21].

For high-impedance line,

$$
\beta l_{L i}=\frac{L_{i} * Z_{o}}{Z_{h}}
$$

For low-impedance line,

$$
\beta l_{C i}=\frac{C_{i} * Z_{l}}{Z_{o}}
$$

So, the physical lengths of these lines are obtained as follows [2], [21],

For high-impedance transmission line length,

$$
l_{L i}=\frac{\lambda_{g L}\left(f_{c}\right)}{2 \Pi} \sin ^{-1}\left(2 \Pi f_{c} \frac{L_{i}}{Z_{h}}\right)
$$

For low-impedance transmission line length,

$$
l_{C i}=\frac{\lambda_{g c}\left(f_{c}\right)}{2 \Pi} \sin ^{-1}\left(2 \pi f_{C} Z_{l} C_{i}\right)
$$

The schematic of the HL-ELPF is shown in Figure 1 and details with dimensions are given in Table I for filter designed using FR4 substrate, where $\mathrm{g}_{0}$ and $\mathrm{g}_{6}$ represent the source and load sections included for matching purpose.

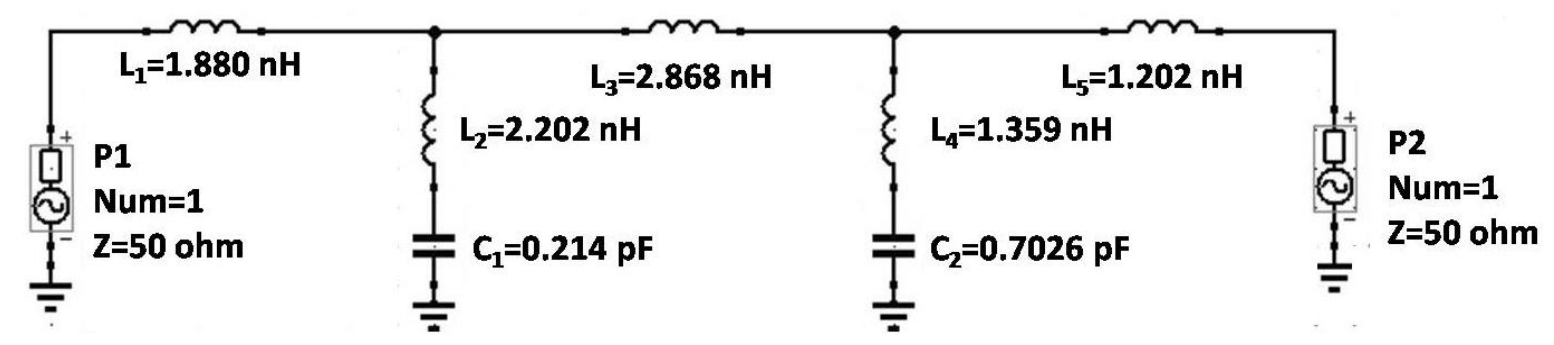

Fig. 1. Schematic of fifth order HL-ELPF.

Brazilian Microwave and Optoelectronics Society-SBMO received 7 July 2020; for review 9 July 2020; accepted 13 Oct 2020 
TABLE I. DETAILS OF THE FIFTH ORDER HL-ELPF.

\begin{tabular}{|c|c|c|c|c|c|c|c|c|}
\hline S.No. & $\begin{array}{c}\text { Immittance } \\
\text { Value }\end{array}$ & $\begin{array}{c}\text { Element } \\
\text { Value }\end{array}$ & Impedance & $\begin{array}{l}\text { W }(\mathbf{m m}) \\
\text { Formula }\end{array}$ & $\begin{array}{c}\text { L (mm) } \\
\text { Formula }\end{array}$ & $\begin{array}{c}\text { W }(\mathbf{m m}) \\
\text { Optimized }\end{array}$ & $\begin{array}{l}\text { L (mm) } \\
\text { Approxi }\end{array}$ & $\begin{array}{c}\text { L (mm) } \\
\text { Optimized }\end{array}$ \\
\hline 1 & $\mathrm{~g}_{1}=0.9448$ & $L_{l}=1.880 \mathrm{nH}$ & $100 \Omega$ & 0.605 & 3.355 & 0.34 & 2.925 & 2.85 \\
\hline 2 & $\begin{array}{l}\mathrm{g}_{2}=1.1060 \\
\mathrm{~g}_{2}{ }^{\prime}=0.2694\end{array}$ & $\begin{array}{l}L_{2}=2.202 \mathrm{nH} \\
C_{l}=0.214 \mathrm{pF}\end{array}$ & $\begin{array}{l}100 \Omega \\
20 \Omega\end{array}$ & $\begin{array}{c}0.605 \\
10.359\end{array}$ & $\begin{array}{c}3.995 \\
0.6468\end{array}$ & 8 & 3.454 & 3.48 \\
\hline 3 & $\mathrm{~g}_{3}=1.4415$ & $L_{3}=2.868 \mathrm{nH}$ & $100 \Omega$ & 0.605 & 5.488 & 0.34 & 4.96 & 5.27 \\
\hline 4 & $\begin{array}{l}\mathrm{g}_{4}=0.6829 \\
\mathrm{~g}_{4}^{\prime}=0.8827\end{array}$ & $\begin{array}{l}L_{4}=1.359 \mathrm{nH} \\
C_{2}=0.7026 \mathrm{pF}\end{array}$ & $\begin{array}{l}100 \Omega \\
20 \Omega\end{array}$ & $\begin{array}{c}0.605 \\
10.359\end{array}$ & $\begin{array}{l}2.376 \\
2.162\end{array}$ & 8 & 2.34 & 3.48 \\
\hline 5 & $\mathrm{~g}_{5}=0.6040$ & $L_{5}=1.202 \mathrm{nH}$ & $100 \Omega$ & 0.605 & 2.092 & 0.34 & 2.084 & 2.85 \\
\hline 6 & $\mathrm{~g}_{0}, \mathrm{~g}_{6}=1$ & - & $50 \Omega$ & 2.797 & 3.83 & 2 & 3.83 & 3.83 \\
\hline
\end{tabular}

As we can see from Table I, a combination of high and low-impedance lines can be used to realized $L_{2} / C_{1}$ and $L_{4} / C_{2}$ resonators [1],[2], which offers high reflections due to unwanted reactance and susceptance at their junctions, respectively. In addition, these combinations will have a large size [2]. To realize the shunt connected series $L-C$ for a three-pole symmetric stepped impedance LPF with the elliptic reponse, the low impedance lines $(C$ 's) are connected in series with high impedance CPW line ( $L$ 's) as DGS to ground plane [34].In order to make a symmetrical structure, initially the following approximation formula is used to estimate a single transmission line for $L_{2} / C_{1}$ and $L_{4} / C_{2}$ resonators [2].

$$
\frac{1}{\left(2 \pi f L_{2}\right)-1 /\left(2 \pi f C_{1}\right)}=B_{2}(f)+\Delta B_{123}(f)
$$

where $B_{2}(f)$ represents a "compensated" susceptance formed by the line elements $L_{2}$ and $C_{l}$, and $\Delta B_{123}(f)$ represents an unwanted total equivalent susceptance due to the first three inductive line elements $\left(L_{1}, L_{2}\right.$ and $\left.L_{3}\right)$ [2].

We estimated the dimensions of low impedance lines $(C$ 's) to represent the shunt connected series LC using equation (7) Similar approach has been applied for the line elements $L_{4}$ and $C_{2}$ to be realized with a single transmission line. The approximate lengths of all sections are given in Table I. An HLELPF with these dimensions is designed on Computer Simulation Technology (CST) software as shown in Figure 2(a) where top layer is synthesized for the symmetrical filter. The optimized dimensions (width W's and length L's) are given in Table I. This complete LPF design has dimensions of $25.59 \mathrm{~mm} \times 11.6 \mathrm{~mm}$. 
As can be seen in Figure 2(b), the cut-off frequency $\left(f_{C}\right)$ is obtained as $4.22 \mathrm{GHz}$ and in the passband centered at $2 \mathrm{GHz}$, the maximum return loss (RL) is $18 \mathrm{~dB}$ and the insertion loss (IL) is $0.41 \mathrm{~dB}$. The bandwidth of stop-band is obtained from 5.1 to $11.2 \mathrm{GHz}$ i.e. $6.1 \mathrm{GHz}$ corresponding to $10 \mathrm{~dB}$ attenuation.
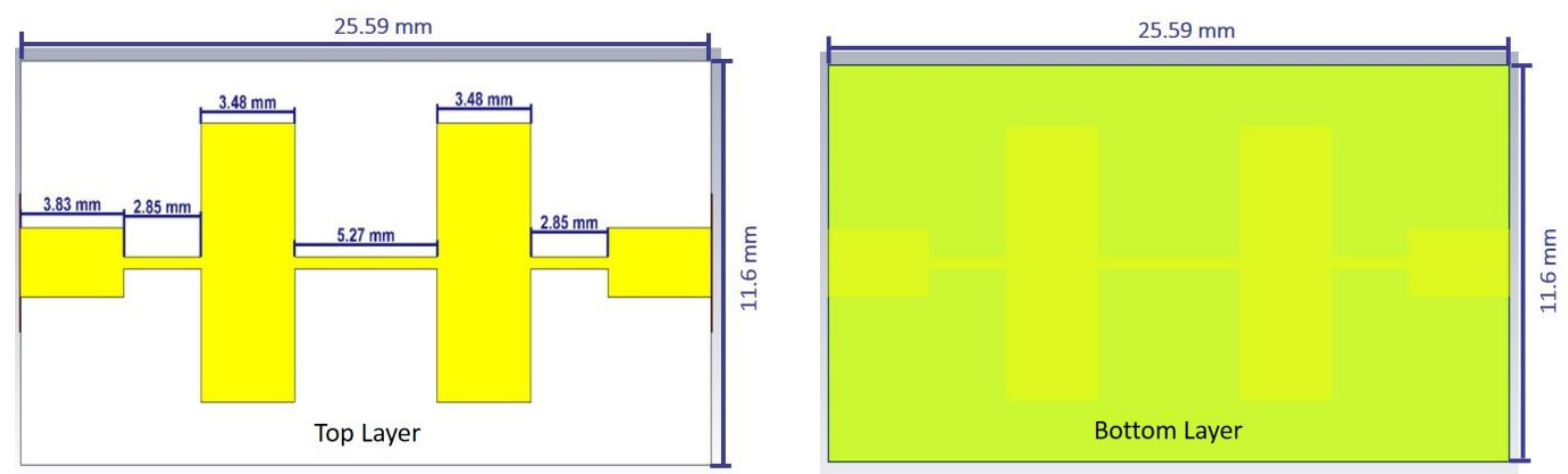

(a)

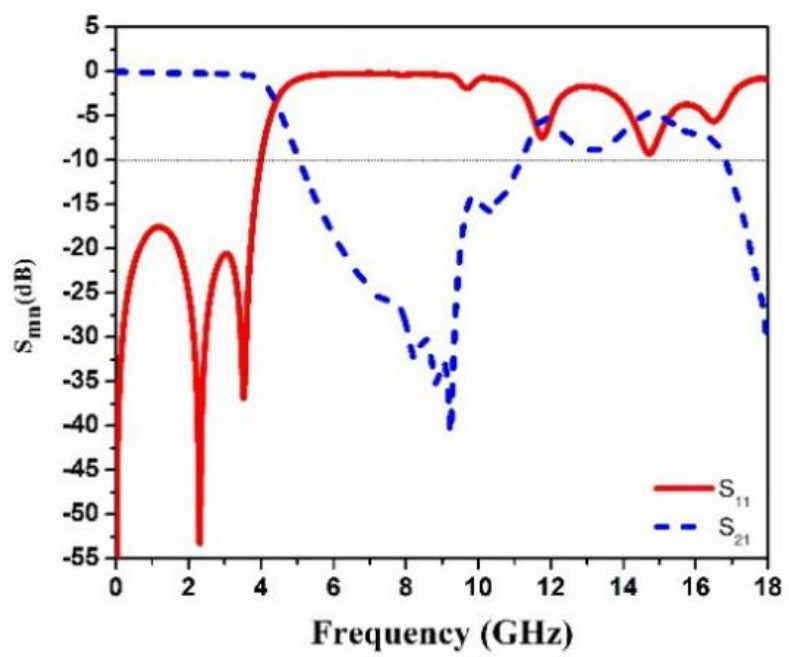

Fig. 2. (a) Fifth order HL-ELPF on CST (Design 1); (b) Simulated S-Parameter response of HL-ELPF.

\section{HL-ELPF WITH DEFECTED GROUND STRUCTURE}

\section{A. Simulation of HL-ELPF with slot and interdigital capacitor DGS}

For an improvement in the stop-band, we introduced a simple rectangular shape slot as a defected ground structure (DGS) just below the three high-impedance lines of top layer [3]. On the bottom layer, the two side slots are made of size of $4.90 \mathrm{~mm}$ width $\times 3.70 \mathrm{~mm}$ length whereas the center slot has the size of $4.90 \mathrm{~mm}$ width $\times 5.60 \mathrm{~mm}$ as illustrated in Figure 3(b) [32]. The etched rectangular slots individually act as a shunt LC resonator, in which the etched area size is controlling the inductance and capacitance is controlled by the distance between the edges. On increment of the etched area series inductance is enhanced with corresponding decrease in the shunt capacitance due to increment in between the edges. Due to the introduction of slots, additional shunt LC resonators are developed shown in Figure 3(c), which alters the current distribution on the bottom layer and so the frequency response also varied with slightly change in the attenuation poles. 


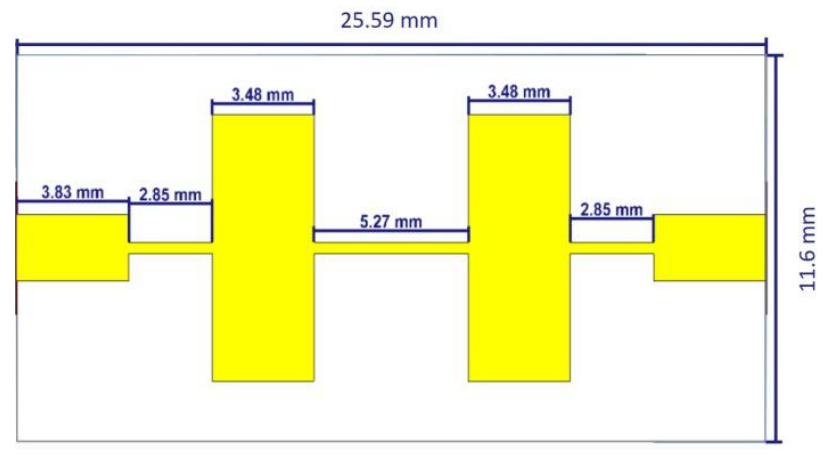

(a)

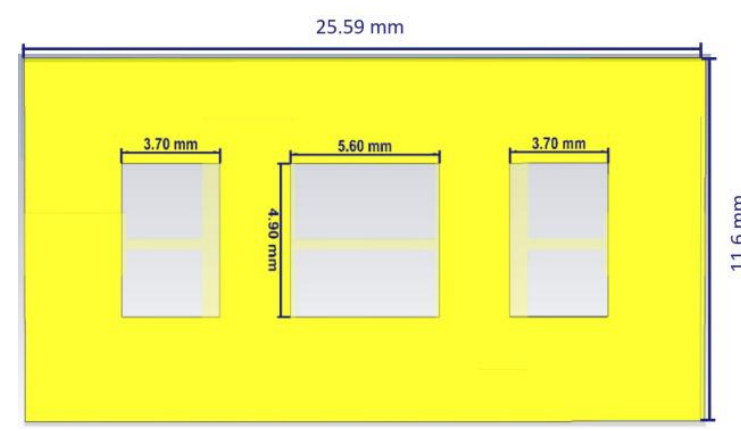

(b)

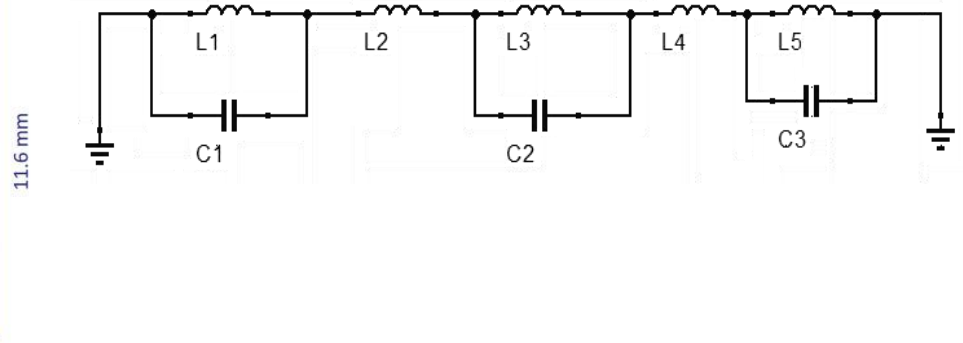

(c)

Fig. 3. (a) Top and (b) bottom layers of HL-ELPF (Design 2) and (c) equivalent lumped prototype of bottom layer.

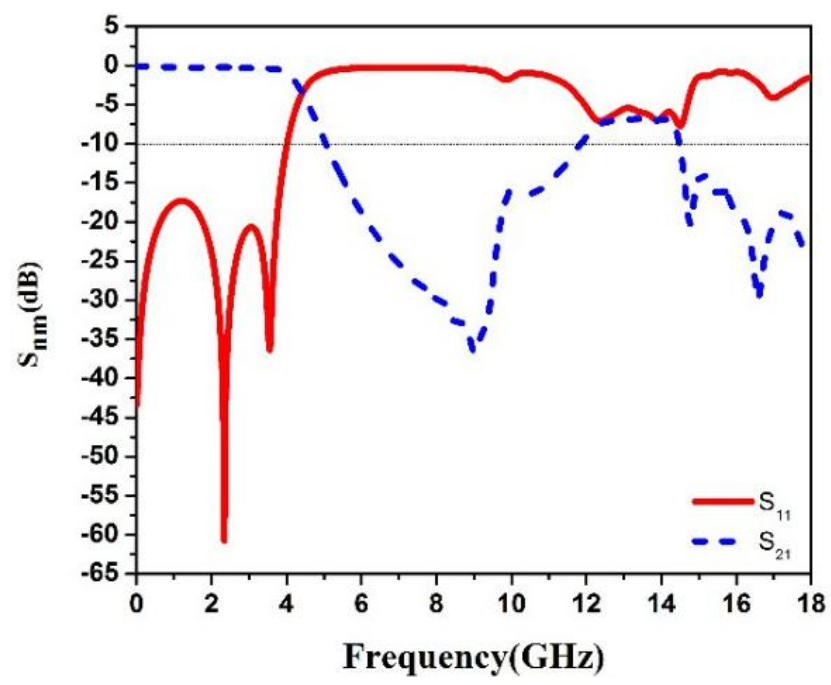

Fig. 4. Simulated S-Parameter response of HL-ELPF with DGS (Design 2).

In respect to the equivalent circuit shown in Figure 3(c), the input impedance $Z_{\text {in }}$ of the bottom layer is modeled using the lumped elements $[35,36]$ as given in the equation (8), 


$$
Z_{i n}=\frac{j \omega L_{1}}{1-\omega^{2} L_{1} C_{1}}+j \omega L_{2}+\frac{j \omega L_{3}}{1-\omega^{2} L_{3} C_{2}}+j \omega L_{4}+\frac{j \omega L_{5}}{1-\omega^{2} L_{5} C_{3}}
$$

The values of equivalent lumped elements are obtained as: $L_{1}=L_{2}=L_{4}=L_{5}=6.12 \mathrm{nH}, L_{3}=9.26 \mathrm{nH}$, $C_{1}=C_{3}=0.0297 \mathrm{pF}, C_{2}=0.0196 \mathrm{pF}$. These lumped values provide the resonant frequencies of 11.8 $\mathrm{GHz}$ and $11.814 \mathrm{GHz}$, respectively due to first (and third) and second resonators. So, as the slot dimensions generated the resonant frequencies of about $11.8 \mathrm{GHz}$, the reflections are found to increase at $11.2 \mathrm{GHz}$ and beyond. So, in 11.8 to $14.25 \mathrm{GHz}$ range, the $\mathrm{S}_{21}$ response is flattened to about $-7 \mathrm{~dB}$. Consequently, stop-band BW increases to $6.8 \mathrm{GHz}$, as shown in Figure 4. In addition, a maximum insertion loss (IL) of $0.53 \mathrm{~dB}$ is found in passband. At $f_{C}=4.25 \mathrm{GHz}$, the phase delay and group delay are obtained as $0.107 \mathrm{~ns}$ and $0.179 \mathrm{~ns}$, respectively. In such slot DGS, changing the slot dimensions can shift the frequency however further reduction in transmission loss is less expected. To further improve the stop-band BW, the DGS can be modified with incorporation of a band stop filter with sufficient bandwidth at the bottom layer.

In the next modification, an interdigital capacitor (IDC) is used as a DGS in place of the rectangular slot resonator as shown in Figure 5(a) and (b) [32]. Here, the metal finger has a dimension of $0.49 \mathrm{~mm} \times 3.2 \mathrm{~mm}$ for targeting high reflection near $12.5 \mathrm{GHz}$ and beyond. First, we placed IDC at the center i.e. in place of the second slot of Design 2 whereas in the second modification on the bottom layer as in Figure 5(b), IDC of same dimensions is placed on two side slots by $90^{\circ}$ rotation and center rectangular slot is kept same [32]. The equivalent circuits of bottom layer with such modifications are shown in Figure 5(c) and (d), respectively. Here, IDC is presented by a series $R L C$ resonator with two shunt capacitor.

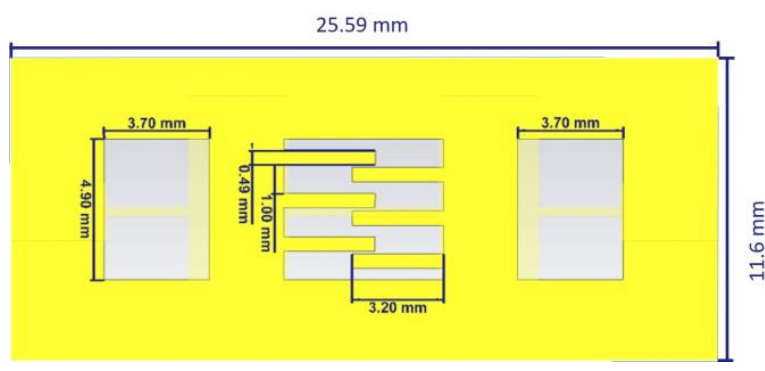

(a)

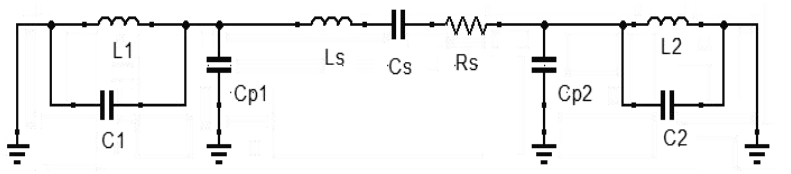

(c)

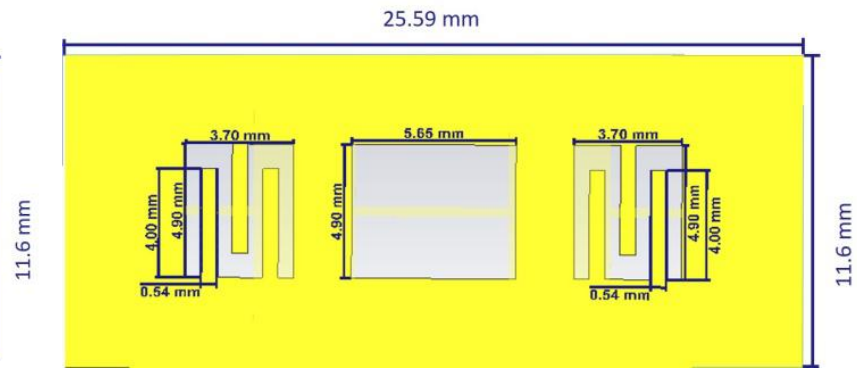

(b)

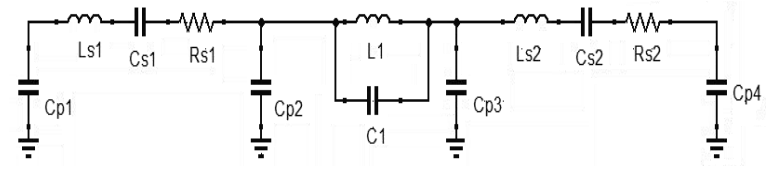

(d)

Fig. 5. Interdigital capacitor on the bottom layer of filter (a) first modification (Design 3), (b) second modification (Design 4), (c) equivalent circuit of bottom layer (Design 3), (d) equivalent lumped prototype of bottom layer (Design 4). 
As the width of the metal finger is directly related to the capacitance of the IDC so, the increment of width of the capacitor leads to decrease in the equivalent capacitance. If the number of fingers is increased with keeping width of the fingers and space between fingers constant, then capacitance of IDC increases with corresponding decrease in the quality factor. With increasing space between the fingers, then the capacitive effect of the IDC is increased. The similar effect can also be observed on the equivalent inductance of the bottom layer. Equivalent circuit of IDC suggested the extension of stop-band by higher capacitance or reduced inductance as IDC is a multi-conductor structure with passband and stop-bands [37]. With the equivalent circuit model as shown in Figure 5(c) [35, 36, 38], the input impedance formula as shown in equation (9) is obtained as,

$$
Z_{i n}=\frac{j \omega L_{1}}{1-\omega^{2} L_{1} C_{1}}+\frac{1}{j \omega\left(C_{p 1}+C_{p 2}\right)}+j \omega L_{s}+\frac{1}{j \omega C_{s}}+R_{s}+\frac{j \omega L_{2}}{1-\omega^{2} L_{2} C_{2}}
$$

The values of equivalent lumped elements of bottom layer (Design 3) are found as: $L_{1}=L_{2}=6.122$ $\mathrm{nH}, C_{1}=C_{2}=0.0297 \mathrm{pF}, R_{s}=0.7003 \Omega, L_{s}=0.8796 \mathrm{nH}, C_{s}=28.9821 \mathrm{pF}, C_{p l}=C_{p 2}=0.17593 \mathrm{pF}$. From these lumped element values, the resonant frequencies are obtained as $11.8 \mathrm{GHz}$ (passed) and 9.1 $\mathrm{GHz}$ (stopped) for the shunt and series/shunt $L C$ resonators, respectively due to the end slots and IDC, with the given dimensions on the bottom layer (Figure 5a).

For the equivalent circuit with $90^{\circ}$ rotation in the side slots shown in Figure 5(d), $Z_{\text {in }}$ is written as [35, $36,38]$,

$$
Z_{\text {in }}=\frac{1}{j \omega\left(C_{p 1}+C_{p 2}\right)}+j \omega L_{s 1}+\frac{1}{j \omega C_{s 1}}+R_{s 1}+\frac{j \omega L_{1}}{1-\omega^{2} L_{1} C_{1}}+\frac{1}{j \omega\left(C_{p 3}+C_{p 4}\right)}+j \omega L_{s 2}+\frac{1}{j \omega C_{s 2}}+R_{s 2}
$$

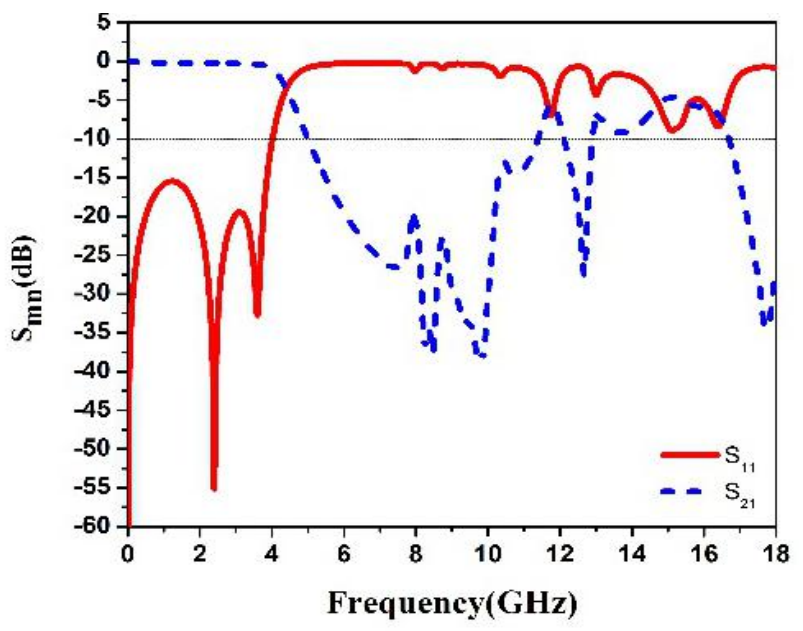

(a)

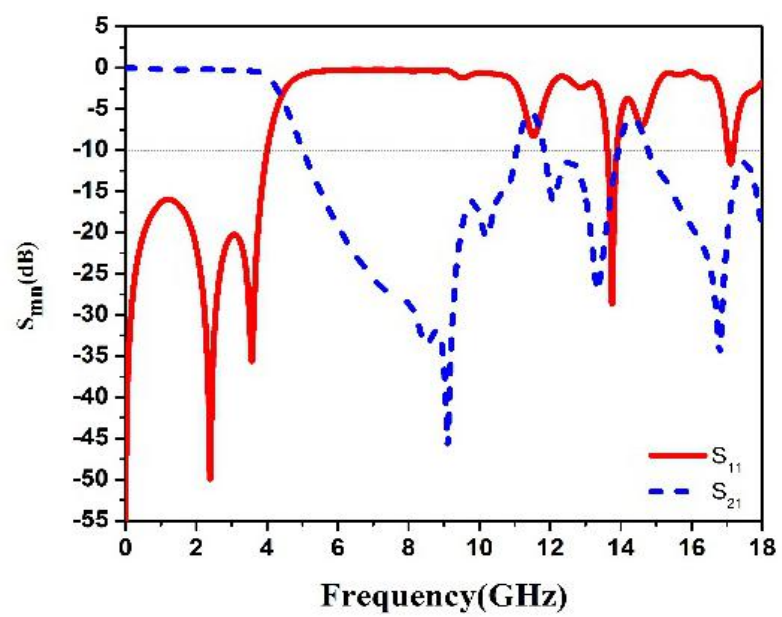

(b)

Figure 6. (a) simulated S-parameter response of HL-ELPF with Design 3 (Figure 5a), and (b) simulated S-parameter response of HL-ELPF with Design 4 (Figure 5b). 
The lumped element values are obtained for the bottom layer as: $L_{1}=9.348 \mathrm{nH}, C_{l}=0.0194 \mathrm{pF}$, $R_{s 1}=R_{s 2}=1.7429 \Omega, L_{s 1}=L_{s 2}=1.117 \mathrm{nH}, C_{s 1}=C_{s 2}=13.546 \mathrm{pF}, C_{p 1}=C_{p 2}=C_{p 3}=C_{p 4}=0.17593 \mathrm{pF}$. With these values the small transmission at $11.8 \mathrm{GHz}$ is possible due to the center (second) slot and beyond it, the side IDCs support the non-transmission of higher frequency. The simulated responses of Design 3 and Design 4 are given in Figure 6(a) and (b), respectively.

As the values of inductance and capacitance generated in the side slots have offered a passband around $11.8 \mathrm{GHz}$ and afterwards the stop-band with minor change in $f_{C}(4.255 \mathrm{GHz}), \mathrm{IL}$ and $\mathrm{RL}$ in pass band as can be seen in Figure 6(a). This modification has slightly decreased the BW of stop-band to $6.5 \mathrm{GHz}$ due to a transmission peak of $-7 \mathrm{~dB}$ at $11.8 \mathrm{GHz}$ due to first and third slots. For the second modification on the bottom layer as in Figure 5(b), the stop-band BW is further reduced to $6.1 \mathrm{GHz}$ with a resonance peak at $11.5 \mathrm{GHz}$ (shown in Figure 6b). However, the reflections are higher beyond this frequency due to two side IDCs till the negative reflection peak at $13.9 \mathrm{GHz}$. Miniaturization of IDC beyond above mentioned dimensions is difficult, which restricts shifting of passband and stopband towards higher frequency. So, if the peak at $11.8 \mathrm{GHz}$ can be addressed by other means, the increase in stop-band BW is possible.

\section{B. Simulation of HL-ELPF with IDC/CSRR}

To achieve stop frequency as $11.8 \mathrm{GHz}$, we have incorporated a complementary split ring resonator (CSRR) arranged in a mirror orientation and IDC, respectively on the place of the side slots and on the centre slot with slight change in dimensions. The physical dimensions of CSRR are taken as follows: width and length of fingers are $0.49 \mathrm{~mm}$ and $4.9 \mathrm{~mm}$, respectively with a gap of $0.4 \mathrm{~mm}$. The top layer, bottom layer and equivalent circuit of bottom layer are shown in Figure 7.

After the insertion of CSRR, the lumped element values of inductor and capacitor decrease significantly in order to increase the stop band frequency from previous designs where only IDC and rectangular slot DGS have been placed. Thus, the characteristic impedance of the bottom layer for such filter structure is increased. From Figure 7(b), an equivalent lumped element circuit of the bottom layer can be designed as shown in Figure 7(c) [33, 38], where IDC is presented by a series $R L C$ resonator with two shunt capacitors and mirrored CSRR is by two shunt $L C$ resonators. The equivalent input impedance formula as shown in equation (11).

$$
Z_{i n}=\frac{j \omega L_{1}}{1-\omega^{2} L_{1} C_{1}}+\frac{j \omega L_{2}}{1-\omega^{2} L_{2} C_{2}}+\frac{1}{j \omega\left(C_{p 1}+C_{p 2}\right)}+j \omega L_{s}+\frac{1}{j \omega C_{s}}+R_{s}+\frac{j \omega L_{3}}{1-\omega^{2} L_{3} C_{3}}+\frac{j \omega L_{4}}{1-\omega^{2} L_{4} C_{4}}
$$




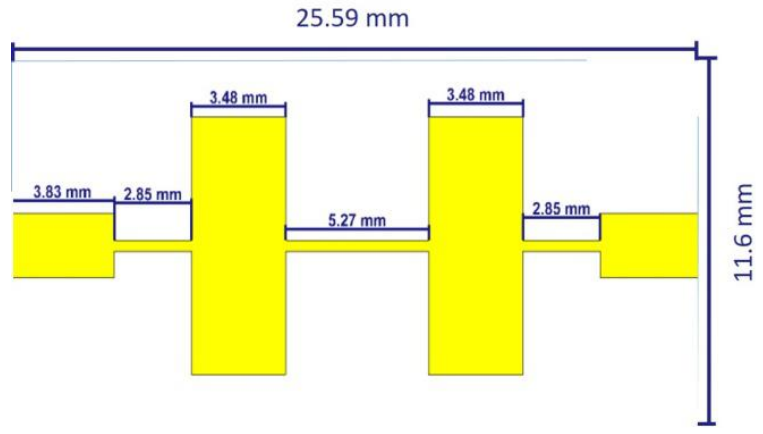

(a)

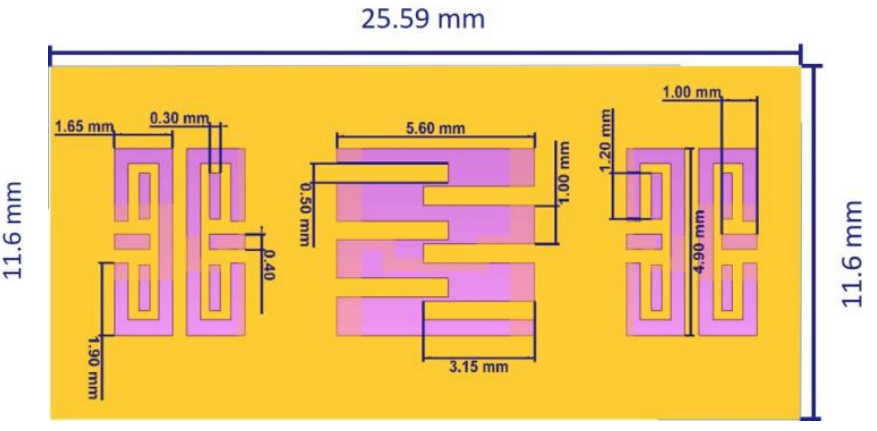

(b)

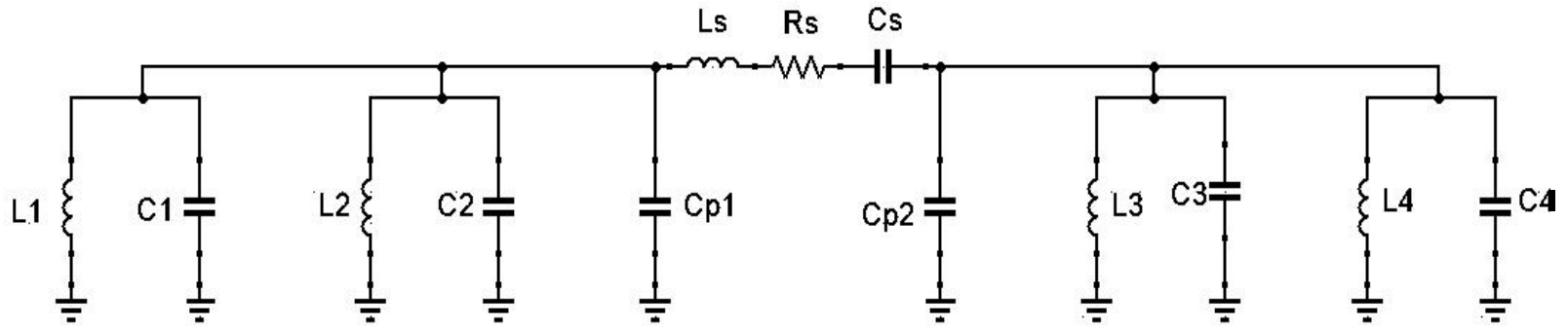

(c)

Fig. 7. (a) Top layer, (b) bottom layer of HL-ELPF with IDC/CSRR (Design 5), and (c) equivalent lumped prototype of bottom layer.

The values of lumped elements are obtained as: $L_{1}=L_{2}=L_{3}=L_{4}=1.13 \mathrm{nH}, C_{1}=C_{2}=C_{3}=C_{4}=1.33 \mathrm{pF}$, $C_{p l}=C_{p 2}=0.22 \mathrm{pF}, L_{s}=1.114 \mathrm{nH}, C_{s}=13.546 \mathrm{pF}, R_{s}=0.34 \Omega$. These values suggested $4.4 \mathrm{GHz}$ as a resonant stop frequency due to CSRR/IDC and so, its harmonics are stopped which will lead to the wide stop band.

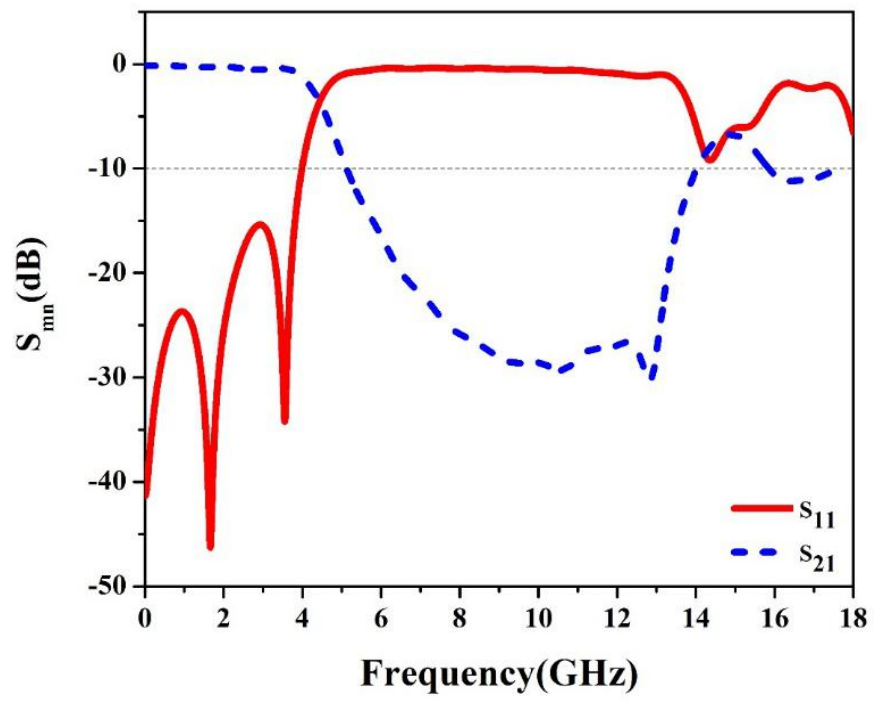

Fig. 8. Simulated S-Parameter response of HL-ELPF with IDC/CSRR. 
In the simulation response of this design shown in Figure 8, the maximum RL of $16 \mathrm{~dB}$ and IL of $0.42 \mathrm{~dB}$ are obtained at $2.9 \mathrm{GHz}$ i.e. ripples in passband are shifted. Although $f_{C}$ increases to 4.34 $\mathrm{GHz}$ due to CSRR, significant increase in stop-band BW is also noticed from $6.5 \mathrm{GHz}$ to $8.8 \mathrm{GHz}$ (i.e. 5.2 - $14 \mathrm{GHz}$ ). This happened due to increment of characteristic impedance by insertion of CSRR which slightly changes the resonant frequency of the overall filter structure as discussed above and the quality factor is also observed to reduce. The further rejection of band from $11.8 \mathrm{GHz}$ to $14 \mathrm{GHz}$ is observed due to CSRRs on the both side slots, which resulted in the wide stopband.

\section{Simulation OF HL-ELPF With U-ShaPED LINE AND IDC/CSRR}

In order to address the compactness of filter, top layer is modified by inserting a U- shaped highimpedance line in place of the straight line as reported in [5]. On top layer of this filter, dimensions of low-impedance line are kept unchanged and on the bottom layer, IDC/CSRR DGS of Figure 7(b) is placed as shown in Figure 9(a). Also to mitigate the problems of parasitic capacitance due to reflections and accumulation of charges at the corners of U-shaped lines, a $50 \%$ mittering is performed with the dimension of $0.42 \mathrm{~mm}$ at the corners in all three U-shaped lines, which is shown in Figure 9(b) keeping the same bottom layer (as in Figure 7b). Lumped equivalent model of its bottom layer is same as mentioned in Figure 7(c), there is no significant change is expected in lumped element values due to U-shaped line in the top layer of the structure. However, the physical length of the filter is reduced. The initial simulated responses of such two designs showed a $3-\mathrm{dB} f_{C}$ close to 4 $\mathrm{GHz}$, but with harmonics at the stop-band. Harmonics at the stop-band occurred due to the different $\mathrm{L}$ values (sizes), so such modifications on top layer deteriorate the flatness of stop band, although the BW of stop-band increased beyond frequency of $16 \mathrm{GHz}$ as reason is mentioned in previous design description. Harmonic reduction achieved by increasing IDC capacitance and shifting the CSRR resonance, which regained flatness in stop-band. Thus, the final optimized bottom layer with dimensions is shown in Figure 9(c).

In the simulation response of HL-ELPF with U-shaped line and optimized IDC/CSRR (Figure 10a), the values are obtained as follows: minimum RL in the pass band as $15 \mathrm{~dB} @ 2 \mathrm{GHz}$ with IL of 0.54 $\mathrm{dB}$, phase delay and group delay as $0.161 \mathrm{~ns}$ and $0.244 \mathrm{~ns}$, respectively at $f_{C}=4.07 \mathrm{GHz}$ and bandwidth of stop-band as $11.01 \mathrm{GHz}(5.07-16.98 \mathrm{GHz})$. Increment in insertion loss is observed due to conductor loss of metal and dielectric loss of dielectric material used in CSRR instead of a slot, which basically depends on loss tangent of the material. Roll-off factor of the filter is also found to be increased upto $6.145 \mathrm{~dB} / \mathrm{GHz}$ due to insertion of DGS elements as more number of elements increases the order of the overall filter $i$. e. sharpness as noticed after simulation. Here two attenuation poles are obtained at $8.484 \mathrm{GHz}$ and $12.51 \mathrm{GHz}$ due to variation of inductance lengths. Also, one resonance peak of $-7.85 \mathrm{~dB}$ in $\mathrm{S}_{11}$ is observed at $14.82 \mathrm{GHz}$. The overall dimension of the filter is reduced to $22.22 \mathrm{~mm} \times 9.5 \mathrm{~mm}$ i.e. by $28.89 \%$ compared to the original design of Figure 2(a). Similar response 
is observed for HL-ELPF with mitered U-shaped line, which is shown in Figure 10(b) except a peak of $-8.35 \mathrm{~dB}$ in $\mathrm{S}_{11}$ at $14.88 \mathrm{GHz}$. However, the advantage of this Design 7 is $\mathrm{BW}$ of $12.0 \mathrm{GHz}$ for stop-band corresponding to $10 \mathrm{~dB}$ attenuation.

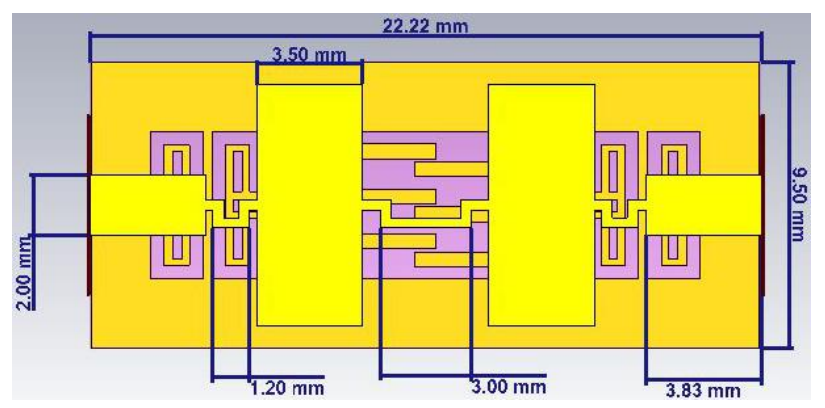

(a)

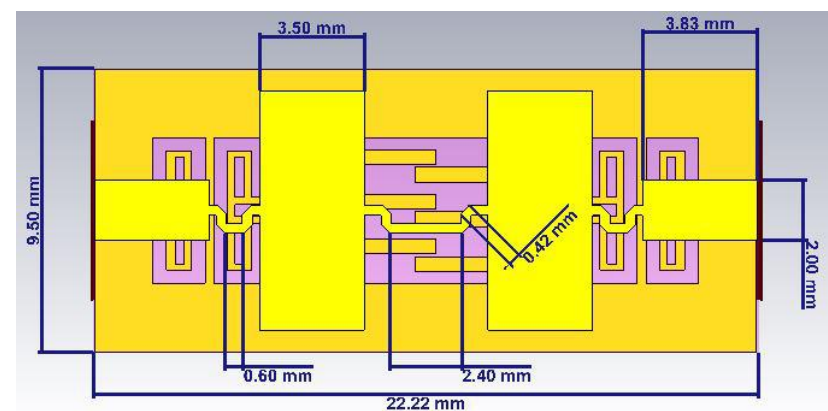

(b)

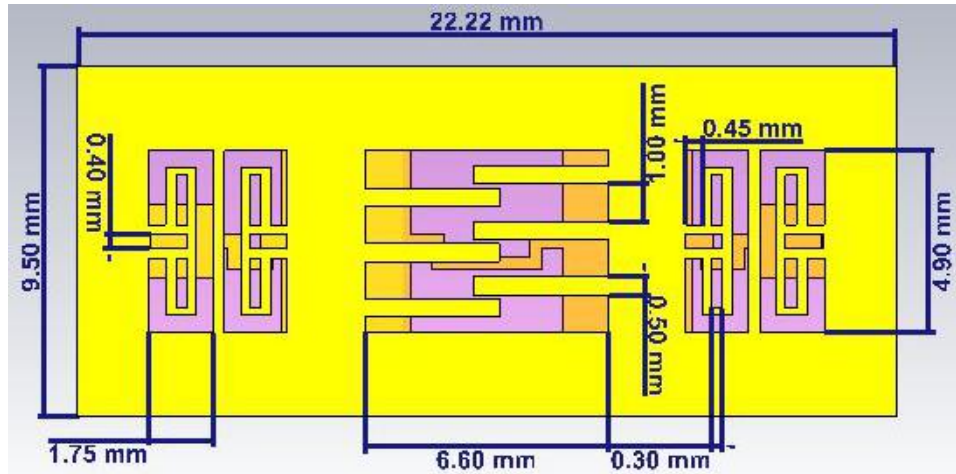

(c)

Fig. 9. (a) Top layer of HL-ELPF with U-shaped line (Design 6) and (b) top layer with mitered U-shaped line (Design 7), and (c) optimized bottom layer with IDC/CSRR DGS.

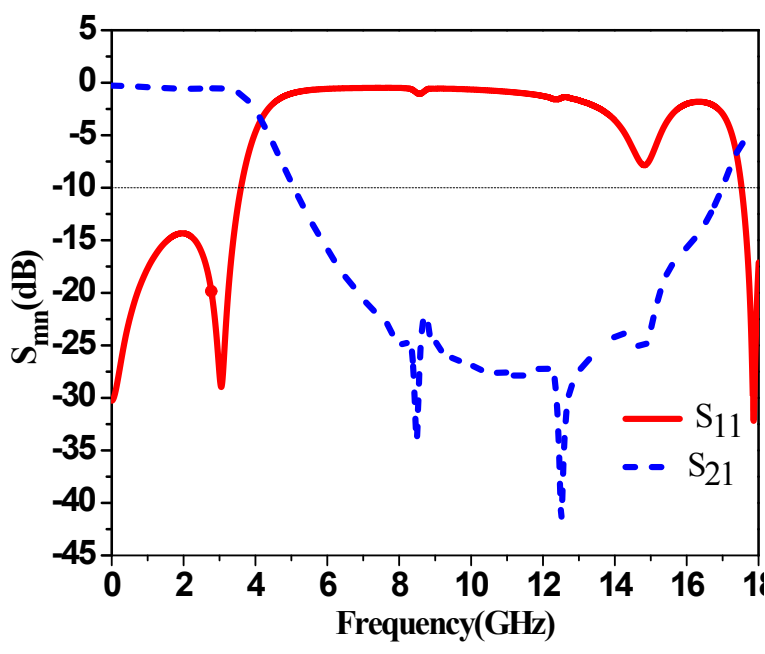

(a)

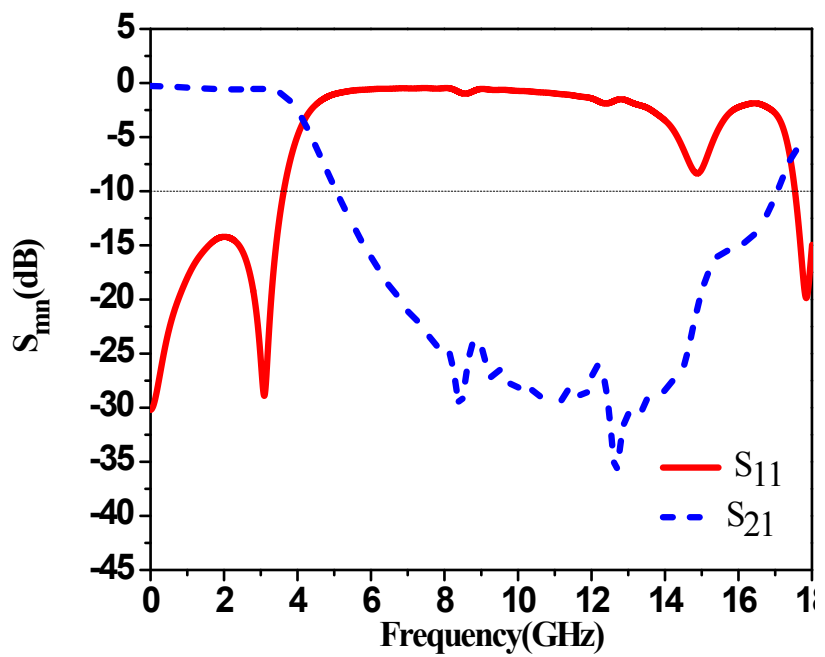

(b)

Fig.10. Simulated S-parameter response of (a) HL-ELPF with U-shaped line and (b) HL-ELPF with mitered U-shaped line. 
The characteristics of low-pass filter designs reported in this work are summarized in Table II as discussed in this section and previous section. The LPF performance parameters like, roll-off rate $(\beta)$, relative stop-band (RSB) bandwidth for $-20 \mathrm{~dB}$ return loss, normalized circuit size (NCS), and figureof-merit (FOM) are calculated from the known relations $[9,18]$ and comparison of last three designs is given in Table III.As given in Table III, the performances of Design 6 and Design 7 are comparable to the earlier reported filters $[8,19,21,31]$. In addition, the proposed filters in this work achieved wide stop-band of $8.15 \mathrm{GHz}$ with high attenuation $(>-20 \mathrm{~dB})$ in the stop-band with the compact circuit size.

TABLE II. CHARACTERISTICS SUMMARY OF HL-ELPF DESIGNS REPORTED IN THIS WORK.

\begin{tabular}{|c|c|c|c|c|c|c|}
\hline S.No. & Designs & $\begin{array}{l}\text { Cut-off } \\
\text { frequency } f_{C} \\
\quad(\mathrm{GHz})\end{array}$ & $\begin{array}{c}\text { Roll-off } \\
\text { (dB/GHz) }\end{array}$ & $\begin{array}{c}\text { Stop band } \\
\text { Bandwidth } \\
\text { (GHz) }(-10 \\
\text { dB) }\end{array}$ & $\begin{array}{c}\text { Phase delay } \\
\text { (ns) }\end{array}$ & $\begin{array}{c}\text { Group delay } \\
\text { (ns) }\end{array}$ \\
\hline 1. & $\begin{array}{c}\text { Design 1 } \\
\text { (Figure 2a) }\end{array}$ & $4.22 \mathrm{GHz}$ & 4.2509 & 6.1 & 0.100 & 0.177 \\
\hline 2. & $\begin{array}{c}\text { Design } 2 \\
\text { (Figure 3ab) }\end{array}$ & $4.25 \mathrm{GHz}$ & 4.753 & 6.8 & 0.107 & 0.179 \\
\hline 3. & $\begin{array}{c}\text { Design } 3 \\
\text { (Figure 5a) }\end{array}$ & $4.255 \mathrm{GHz}$ & 4.724 & 6.5 & 0.102 & 0.178 \\
\hline 4. & $\begin{array}{c}\text { Design } 4 \\
\text { (Figure } 5 \mathrm{~b} \text { ) }\end{array}$ & $4.255 \mathrm{GHz}$ & 4.2563 & 6.1 & 0.106 & 0.177 \\
\hline 5. & $\begin{array}{l}\text { Design } 5 \\
\text { (Figure 7) }\end{array}$ & $4.34 \mathrm{GHz}$ & 4.23323 & 8.8 & 0.100 & 0.179 \\
\hline 6. & $\begin{array}{c}\text { Design } 6 \\
\text { (Figure 9a,c) }\end{array}$ & $4.07 \mathrm{GHz}$ & 6.20611 & 11.01 & 0.161 & 0.244 \\
\hline 7. & $\begin{array}{c}\text { Design } 7 \\
\text { (Figure } 9 \mathrm{~b}, \mathrm{c} \text { ) }\end{array}$ & $4.08 \mathrm{GHz}$ & 6.14489 & 12.0 & 0.160 & 0.231 \\
\hline
\end{tabular}

TABLE III. PERFORMANCE COMPARISONS AMONG PROPOSED DESIGNS OF ELPF.

\begin{tabular}{ccccc}
\hline Design & $\boldsymbol{\beta ( d B / G H z )}$ & RSB & NCS & FOM \\
\hline Design 5 & 4.23323 & 0.683 & $0.483 \times 0.216$ & 27.7753 \\
Design 6 & 6.20611 & 0.762 & $0.419 \times 0.202$ & 56.0297 \\
Design 7 & 6.14489 & 0.749 & $0.417 \times 0.202$ & 54.6361 \\
\hline
\end{tabular}

\section{CONCLUSION}

A fifth order hi-lo elliptic LPF was simulated for the cut-off frequency of $4.2 \mathrm{GHz}$ on FR4 substrate for a wide band stop response. The results showed that the insertion loss in the low frequency passband is less than $0.5 \mathrm{~dB}$ from $\mathrm{DC}$ to $4 \mathrm{GHz}$ and the stop-band of $6.1 \mathrm{GHz} \mathrm{BW}$ is obtained corresponding to the $10 \mathrm{~dB}$ attenuation for the initial filter design. On improvisation using various DGSs like slot, interdigital capacitor and CSRR, the stop-band BW increases to $8.8 \mathrm{GHz}$ without affecting other parameters of this filter. Further replacing high impedance line on top layer by 
U-shaped line with mitering leads to compactness of filter by about $29 \%$ and offered the wide stopband $\mathrm{BW}$ of $12 \mathrm{GHz}$ with attenuation level higher than $-10 \mathrm{dBas}$ well, which equals to $3 f c$. The final compact proposed filter has the dimensions of $22.22 \mathrm{~mm} \times 9.5 \mathrm{~mm}$, in which RL, IL, roll-off rate and stop band BW are improved by about $9.7 \%, 26.5 \%, 42 \%$ and $80 \%$, respectively. In future, modifications on the top layer like use of "S" or "C" shaped line for compact filter can be applied and to improve the stop-band response, slot on capacitive line of top layer or different shapes of slots in bottom plane such as elliptic, semicircular, triangular, pi-shaped can be incorporated.

\section{ACKNOWLEDGMENT}

The work was supported by the Research \& Development Scheme 2015-16 of the University of Delhi (RC/2015/9677 dated $15 / 10 / 2015)$

\section{REFERENCES}

[1] D.M.Pozar: "Microwave Engineering," John Wiley \& Sons Inc; 2012.

[2] H. J. Sheng, M. J. Lancaster, "Microstrip Filters For RF/Microwave Applications," John Wiley And Sons Inc, pp 29-75, pp. 117-121, 2001.

[3] Y. Yang, X. Zhu and N. C. Karmakar, "A Novel Microstrip Lowpass Filter Using Compact Microstrip Resonant Cells and Uniquely Shaped Defected Bottom Structures," Microwave Opt Technol Lett, vol. 54, pp. 2462-2464. 2010.

[4] M. A. Zhewang, K. Nomiyama and Y. Kobayashi, "Microstrip Lowpass Filters with Reduced Size and Improved Stop-band Characteristics," IEICE Trans Electron, vol. E88-C, pp. 62-67, 2005.

[5] A. Rajput, K. Patel and A. Birwal, "Compact Microstrip Low-pass Filter Design Using U-Shaped Folded HighImpedance Line," Microw Opt Technol Lett, vol. 60, pp. 1812-1815, 2018.

[6] M. Hayati, F. Shama, "Compact Microstrip Low-Pass Filter with Wide Stop-band Using Symmetrical U-Shaped Resonator," IEICE Electronics Express, vol. 9, no. 3, pp. 127-132, 2012.

[7] M. R. Khezeli , M. Hayati and A. Lotfi, "Compact Wide Stop-band Lowpass Filter Using Spiral Loaded Tapered Compact Microstrip Resonator Cell,” International Journal of Electronics, vol. 101, no. 3, pp. 335-382, 2014.

[8] L. H. Hsieh and K. Chang, "Compact Elliptic-Function Low-Pass Filters Using Microstrip Stepped-Impedance Hairpin Resonators," IEEE Trans on Microwave Theory and Techniques, vol. 51, no. 1, pp. 193-199, 2003.

[9] J. L. Li, S. W. Qu and Q. Xue,"Compact Microstrip Lowpass Filter With Sharp Roll-Off And Wide Stop-Band," Electronics Letters, vol. 45, no.2, pp. 110-111, 2009.

[10] M. Yang, J. Xu and Q. Zhao et al, "Compact Broad Stop-band Lowpass Filters Using SIRs-Loaded Circular Hairpin Resonators," Progress in Electromagnetics Research, vol. 102, pp. 95-106, 2010.

[11] V. K. Velid and S. Sanyal, "Sharp Roll-Off Lowpass Filter with Wide Stop-band Using Stub-Loaded CoupledLine Hairpin Unit," Microwave and Wireless Components Letters, vol. 21, no.6, pp. 301-303, 2011.

[12] M. Hayati, F. Shama and H. Abbasi, "Compact Microstrip Lowpass Filter with Wide Stop-band and Sharp RollOff Using Tapered Resonator," International Journal of Electronics, vol. 100, no. 12, pp. 1751-1759, 2013.

[13] M. Hayati and A. Lotfi, "Elliptic-Function Lowpass Filter with Sharp Cut-off Frequency Using Slit-Loaded Tapered Compact Microstrip Resonator Cell," Electronics Letters,vol.46, no. 2, pp. 143-144, 2010.

[14] J. Wang, L. J. Xu , S. Zhao, Y. X. Guo et al, "Compact Quasi-Elliptic Microstrip Lowpass Filter With Wide Stop-band," Electronics Letters, vol. 46, no. 20, pp. 1384-1385, 2010.

[15] J. Wang, H. Cui and G. Zhang, "Design of Compact Microstrip Lowpass Filter with Ultra-Wide Stop-band," Electronics Letters, vol. 48, no. 14, pp. 854-856, 2012.

[16] J. P. Wang ,L. Ge , Y. X. Guo and W. Wu, "Miniaturised Microstrip Lowpass Filter With Broad Stop-band And Sharp Roll-Off," Electronics Letters, vol. 46, no. 8, pp. 573-575, 2010.

[17] M. Hayati, M. Validi, F. Shama et al,"Compact Microstrip Low-pass Filter with Wide Stop-band Using P Shaped Resonator,"Journal of Microwaves, Optoelectronics and Electromagnetic Applications,vol.15, no. 4, pp. 309-318, 2016.

[18] M. Hayati, F. Shama, "A Compact Lowpass Filter with Ultra Wide Stop-band Using Stepped Impedance Resonator," Radioengineering,vol. 26, no. 1, pp. 269-274, 2017.

[19] D. Packiaraja, K. J. Vinoy, M. Ramesh et al, "Design of Compact Low-pass Filter with Wide Stop-band Using Tri-Section Stepped Impedance Resonator," Int. J. Electron. Commun. (AEÜ),vol. 65, pp. 1012- 1014, 2011.

[20] S. H. Kazemi and M. A. Hayati "Compact Microstrip Lowpass Filter with Wide Stop-band," International Journal of Microwave and Wireless Technologies, vol. 11, no. 9, pp. 885-893, 2019.

[21] A. O. Ertay and S. Simsek, "Design of Elliptic-Function Microstrip Filters with Defected Bottom Structures," In: PIERs Proceedings, Stockholm, Sweden, pp. 1838-1842, 2013. 
[22] J. X. Chen, J. L. Li , K. C. Wan et al, "Compact Quasi-Elliptic Function Filter Based On Defected Bottom Structure," In: IEE Proceedings: Microwaves, Antennas and Propagation, vol. 153, no. 4, pp. 320-324, Aug. 2006.

[23] A. B. Abdel-Rahman, A. K. Verma , A. Boutejdar et al, "Compact Stub Type Microstrip Bandpass Filter Using Defected Bottom Plane,"IEEE Microwave and Wireless Components Letters, vol. 14, no. 4, pp. 136 - 138, 2014.

[24] W. H. Tu and K. Chang, "Compact Microstrip Low-Pass Filter with Sharp Rejection," IEEE Microwave and Wireless Components Letters,vol. 15, no. 6, pp. 404-406, 2005.

[25] M. Al Sharkawy, A. Boutejdar and E. G. Mahmoud,"Design of Ultra-Wide Stop-Band DGS Low-Pass Filter Using Meander- and Multilayer Techniques," Microwave and Optical Technology Letters, vol. 55, no. 6, pp. 1276$1281,2013$.

[26] C. Chang, W. Chen and Z. Zhang, "A Novel Dual-Mode Dual-Band Bandpass Fllter with DGS," In: PIERS Proceedings. Marrakesh, Morocco, pp. 1723-1726, Mar. 2011.

[27] A. B. Abdel-Rahman, A. K. Verma , A. Boutejdar et al, "Control Of Bandstop Response Of Hi-Lo Microstrip Low-Pass Fllter Using Slot In Bottom Plane," IEEE Transactions on Microwave Theory and Techniques, vol. 52, no. 3, pp. 1008-1013, 2004.

[28] A. Kumar, A. Sawant and M. V. Kartikeyan, "Investigation of Fractal DGS Microwave Fllters," In: Proceedings of 2013 National Conference On Communications (NCC), pp.1-4, Feb. 2013.

[29] S. V. Makki Al-Din, A. Ahmadi, S. Majidifar et al, "Sharp Response Microstrip LPF Using Folded Stepped Impedance Open Stubs," Radio Engineering, vol. 22, no. 1, pp. 328-332,2013.

[30] R. Y. Yang,Y. L. Lin,C. Y. Hung et al, "Design of A Compact And Sharp-Rejection Low-Pass Filter With a Wide Stop Band," Journal of Electromagnetic Waves and Applications, vol. 26, no. 17-18, pp.2284-2290. 2012.

[31] A. Tirado-Mendez , H. Jardon-Aguilar , R. Flores-Leal et al.“Improving Frequency Response Of Microstrip Filters Using Defected Bottom and Defected Microstrip Structures,” Progress in Electromagnetic Research C, vol. 13, pp. 77-90, 2010 .

[32] D. Gadvi and U. Shah, "Microstrip Low-pass Filter Designs Using Defected Bottom Structure," International J of Research in Engg Tech, vol. 4, no. 10, pp. 43-48, 2015.

[33] R. Selvaraju, M. H. Jamaluddin, M. R. Kamarudin et al,"Complementary Split Ring Resonator for Isolation Enhancement in 5G Communication Antenna Array,” Progress in Electromagnetics Research C, vol. 83, pp. 217228, 2018.

[34] M. C. Velazquez-Ahumada, J. Martel, and F. Medina, "Low-pass Elliptic Filters Using Mixed Microstrip-CPW Technologies," PIERS Online, vol. 3, no. 7, pp. 997-999, 2007.

[35] M. M. Rehaman, M. S. Islam, H. Y. Yong, T. Alam, M. T. Islam, "Performance Analysis of a Defected GroundStructured Antenna Loaded with Stub-Slot for 5G Communication,” Multidisciplinary Digital Publishing Institute, vol. 19, no. 11, 2634, Sept. 2019.

[36] M. K. Khandelwal, B. K. Kanaujia, S. Kumar, "Defected Ground Structure: Fundamentals, Analysis, and Applications in Modern Wireless Trends," International Journal of Antennas and Propagation, vol. 2017, Article ID 2018527, 22, 2017.

[37] F. P. Casares-Miranda , P. Otero , E. Márquez-Segura et al, "Wire Bonded Interdigital Capacitor," IEEE Microwave and Wireless Components Letters, vol. 15, no. 10, pp. 700-702, 2005.

[38] R. S. Beeresha, A. M. Khan, M. Reddy H V, "Design And Optimization Of Interdigital Capacitor," International Journal of Research in Engineering and Technology, vol. 5, no. 21, pp. 73-78, Nov. 2016. 